\title{
EFFICIENTLY MEMORIZING WORDS WITH THE HELP OF WORD CARDS AND "HAND COMPUTER": THEORY AND APPLICATIONS
}

\author{
JAN-AR.JEN MONDRIA AND SIEBRICH MONDRIA-DE VRIES
}

\author{
University of Groningen, Groningen, The Netherlands
}

\begin{abstract}
An efficient method for memorizing words is the "hand computer": a deck of cards in which word cards are combined with a repetition system on the basis of ever bigger intervals. The hand computer, based on two learning-psychological principles, namely distributed practice and retrieval practice, has various advantages over traditional memorizing with the help of either contextualized or non-contextualized inflexible lists. The system, with which positive results have been obtained in several places, is suitable for all types of learners and for all levels, and is very flexible with respect to content (words, idioms, language functions, pronunciation). The system has also been implemented in a few CALL-programs.
\end{abstract}

\section{INTRODUCTION}

Inherent in the learning of a foreign language is the learning of a large number of words. Learning words, however, is a time-consuming activity, and especially so as some of the words learned are forgotten relatively quickly. Word cards (also called "flashcards": cards with - in the simplest form-the foreign-language word form on one side and the translation on the other), especially when they are combined with a repetition system, can significantly contribute to a more efficient process of vocabulary acquisition. Since working with word cards, with or without repetition system, is related to that part of the process of vocabulary acquisition which we call "memorizing", we shall first briefly go into the role of memorizing within this process (Section 2). Subsequently, we shall signal some of the problems that are inherent in the traditional way of memorizing, i.e. memorizing with the help of lists, in whatever form (Section 3). Since one of the weak spots of traditional memorizing is the lack of repetition, by which forgetting is promoted, we shall discuss some models from the psychology of learning which are intended to combat forgetting (Section 4). A very special implementation of these models is the so-called hand computer of Leitner (1972), which combines word cards with an ingenious repetition system (Section 5 ). We shall discuss the advantages of word cards and the hand computer (Section 6), and subsequently we shall mention various applications (Section 7). We shall wind up with a conclusion (Section 8).

\section{THE ROLE OF MEMORIZING WITHIN THE PROCESS OF VOCABULARY ACQUISITION}

Within the process of vocabulary acquisition we distinguish in principle three stages:

In the first stage, the presentation, the learner is confronted with the unknown word for the first time. The context in which a word is presented can be very different: (a) contextless 
(a meaningful context is lacking); (b) situational context (a non-linguistic context); (c) textual context (a linguistic context).

In the second stage, semanticizing, ${ }^{1}$ the meaning of the unknown word becomes clear, or is made clear, e.g. by (a) giving the meaning, (b) guessing with the help of context and/or word form, or (c) looking it up. Combinations are also possible.

In the third stage, the consolidation, the relation between word and word meaning is made lasting; i.e. activities take place as a result of which the learner, even after some time, still knows what a particular word means. Consolidation may take place in three ways: (a) through incidental learning (learning without the learner realizing it, e.g. by reading); (b) by practising; (c) through memorizing (learning by heart the relation between a word and its meaning). These last three activities may take place complementary to each other.

This article will be about memorizing, especially memorizing with the help of word cards and the hand computer. In our discussion of word cards and the hand computer, further on in this article, we will assume that the presentation and semanticizing have already taken place. This will in most cases have taken place in a particular situational or textual context. The effect of this context will continue to be felt, even if a word is given in isolation (i.e. contextless) on a card: the context resonates along with the word as it were, and may function as a cognitive foothold. It is even possible to write down the context on the card as a cognitive foothold [cf. Van Parreren and Schouten-Van Parreren (1978: pp. 33-34)]. Therefore, working with word cards should not be seen as "learning words contextlessly".

\section{THE PROBLEMS OF THE TRADITIONAL WAY OF MEMORIZING}

In the process of vocabulary acquisition quite some time is spent on memorizing. Unfortunately, the results often leave a lot to be desired. The cause of this is that the traditional forms of memorizing, which are still very often used, such as memorizing with the help of a word list from a coursebook, a vocabulary book or a vocabulary notebook, in short all forms of memorizing with the help of either contextualized or non-contextualized inflexible lists, are inefficient-something that was indeed observed as long ago as Weber and Denninghaus (1960)-because they do not take into account the following data from learning theory:

(1) The degree of difficulty of the words to be learned rather varies [cf. Higa (1965) and Rodgers (1969)], as a result of which some words are learned faster than other ones. In the process of memorizing with the help of lists this will lead to learners, as memorizing progresses, devoting quite some time to "overlearning" of the increasing number of words known by then, which are brought to their attention time and time again. This time is better spent on the words that are not yet known.

(2) The knowledge of vocabulary strongly differs from learner to learner: words that are unknown to one learner are known to the other, even if they use the same coursebook [cf. Saragi et al. (1978: p. 72)]. As a result of this many lists ${ }^{2}$ will contain words which are known already to part of the learners, and which in learning are unnecessarily often brought to their attention. In this instance, too, time is better spent on words that are not yet known. 
(3) The order in which words are listed often wrongly offers help in remembering (Nation, 1990: p. 127). This often results in words being "known" within the list, but not outside it because the support of the list is then lacking, the so-called "list effect".

(4) In the course of time knowledge of vocabulary decreases (in particular the knowledge of newly-learned words), if it is not reactivated from time to time. This often happens in practice, because in many coursebooks the vocabulary learned insufficiently recurs in subsequent lessons. ${ }^{3}$ It is the latter problem, forgetting, that we should like to go into in the next section.

\section{THE BATTLE AGAINST FORGETTING}

Ever since Ebbinghaus (1885) we have been familiar with the general characteristic of forgetting: immediately after learning knowledge decreases rapidly, but subsequently it does so much less quickly (see Fig. 1, in which the horizontal axis represents the time interval, and the vertical axis the retention percentage).

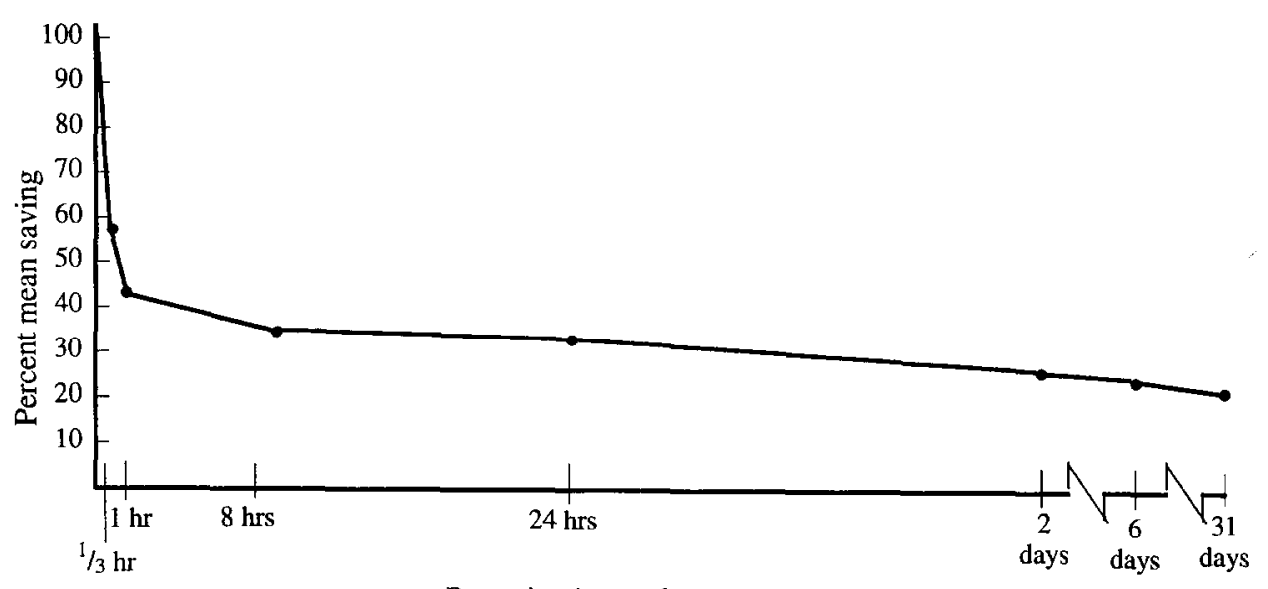

Retention interval

Fig. 1. Forgetting curve (Ebbinghaus, 1885).

On the basis of this forgetting curve Pimsleur (1967) designed a learning-psychological model, called graduated interval recall, in which he posits that one should revise at a moment when one still stands a decent chance of knowing the meaning, say $60 \%$. If, at that moment, the learner does not remember the meaning of a word, (s)he is confronted with it once more, which brings the level of knowledge to $100 \%$ again (see Fig. 2). Owing to the fact that knowledge decreases less rapidly after each repetition, the interval between the reviews will increase. 


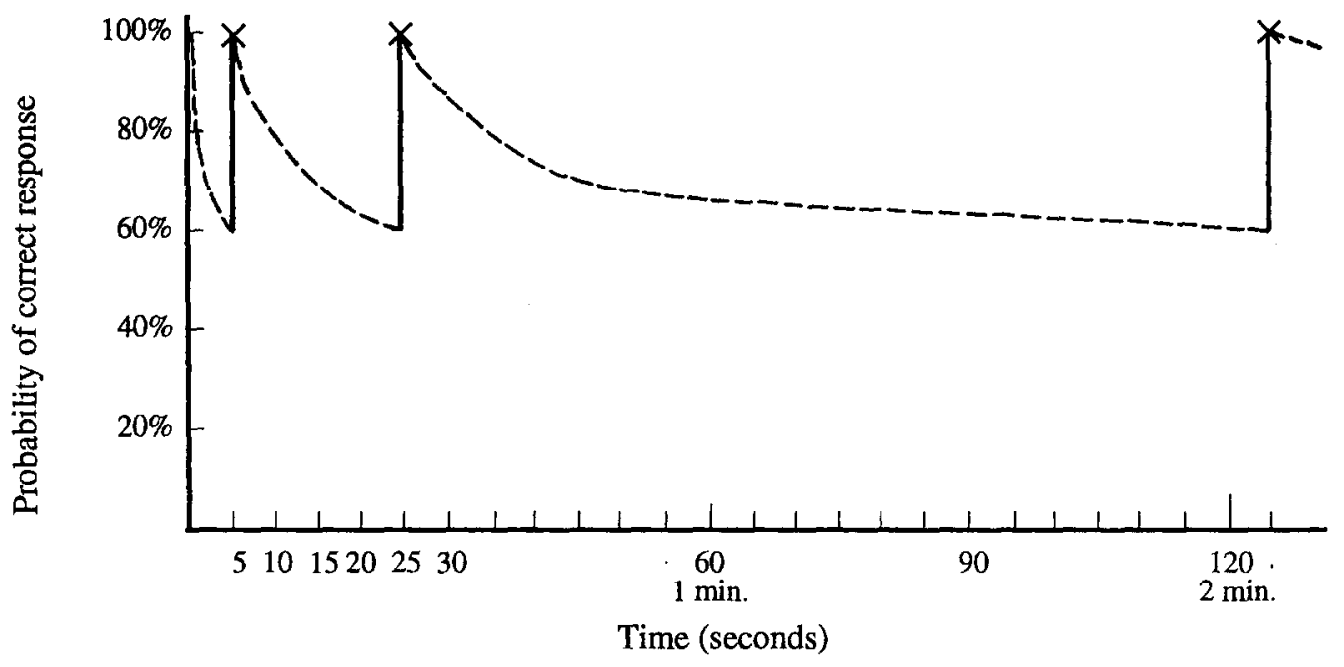

Fig. 2. Pimsleur's memory schedule (Pimsleur, 1967).

The notion of ever bigger review intervals can also be found in Lado (1964) and Oxford (1990). According to Lado's (hypothetical) law of geometric increase of permanence the length of time that a response may be remembered, i.e. recalled at will, increases by a ratio of 2 or 3 times the length of time preceding its previous correct exercise with intent to learn (Lado, 1964: p. 45). Oxford's Structured Review also entails reviewing at different intervals, e.g. $15 \mathrm{~min}$ later, $1 \mathrm{hr}$ later, $3 \mathrm{hr}$ later, the next day, 2 days later, 4 days later, the following week, 2 weeks later, and so on until the material becomes more or less automatic (Oxford, 1990: pp. 66-67).

The experimental evidence that learning through ever bigger intervals is a superior memory technique, was provided by Landauer and Bjork (1978). On the basis of their research they pleaded in favour of the expanding rehearsal strategy. This strategy advocates that a given item should be initially tested after a very brief delay. If the subject correctly recalls it, the delay should be systematically increased, whereas if (s)he is wrong the delay should be shortened. An example of such a schedule, exemplified for the learning of French words, is shown in Table 1.

The explanation for the superiority of the expanding rehearsal strategy lies in two learning-psychological principles which are combined in this strategy, namely distributed practice $^{6}$ and retrieval practice $e^{7,8}$. The principle of distribution of practice, which is known as an extremely robust and powerful phenomenon (Anderson, 1990: p. 207), implies that an item is more profitably repeated if it is distributed (i.e. over time) than a few times in close succession (so-called "massed practice"). The principle of retrieval practice implies that the act of successfully recalling an item increases the chance that the item will be remembered. Recalling the item even leads to better retention than presenting it again ${ }^{9}$. This means that, in 
Table 1. Example of the expanding rehearsal strategy (Landauer and Bjork, 1978)

\begin{tabular}{|c|c|c|c|}
\hline Teacher & Learner & Teacher & Learner \\
\hline $\begin{array}{c}\text { the stable = l'écurie } \\
\text { the stable? }\end{array}$ & l'écurie & $\begin{array}{l}\text { the horse? } \\
\text { the grass? }\end{array}$ & $\begin{array}{l}\text { le cheval } \\
\text { l'herbe }\end{array}$ \\
\hline $\begin{array}{c}\text { the horse = le cheval } \\
\text { the horse? } \\
\text { the stable? } \\
\text { the horse? } \\
\text { the grass = l'herbe } \\
\text { the grass? } \\
\text { the stable? }\end{array}$ & $\begin{array}{l}\text { le cheval } \\
\text { l'écurie } \\
\text { le cheval }\end{array}$ & $\begin{array}{c}\text { the church = l'église } \\
\text { the church? } \\
\text { the grass? } \\
\text { the church? } \\
\text { the stable? } \\
\text { the grass? } \\
\text { the horse? }\end{array}$ & $\begin{array}{l}\text { l'église } \\
\text { l'herbe } \\
\text { l'église } \\
\text { l'écurie } \\
\text { l'herbe } \\
\text { le cheval }\end{array}$ \\
\hline
\end{tabular}

learning, subjects will be helped by being tested at a time when they can still remember an item. Landauer and Bjork tried to combine these apparently conflicting principles and suggested that the optimum is to test a given item at the longest delay compatible with correct recall. As learning proceeds this delay will increase, suggesting that one should use a strategy of expanding rehearsal.

Additional positive elements in the expanding rehearsal strategy, which, incidentally, may be used in learning a wide range of tasks [cf. Rea and Modigliani (1988)], are: (a) that a learner makes few mistakes, as a result of which (s)he is not easily discouraged (Baddeley, 1983: p. 29); and (b) that because of the ever bigger intervals at which words are revised sufficient room is left for the introduction of new items (Bjork, 1988: p. 399).

Weak points of this system are in our opinion that with the independent application of the strategy to a list of words (i.e. without the teacher functioning as "prompter"): (a) it demands quite some of the learner's attention to organize his/her learning in this way; (b) the place of the word on the list may wrongly offer help; (c) the words in the tail of the list get relatively little attention. In Landauer and Bjork's experiment these objections were actually overcome by making the learners learn by means of a prepared deck of cards, in which all target-items occurred an equal number of times, with repetitions at ever bigger intervals. Another way of overcoming these objections is programming the learning process with the help of a computer, such as Siegel and Misselt (1984) did during their word-learning experiment.

\section{LEITNER'S HAND COMPUTER}

A special, and at the same time practically easily manageable implementation of the notion of the ever bigger intervals is Leitner's hand computer $(1972)^{10}$, a deck of cards with word cards with a sophisticated repetition system. This deck of cards (in its simplest form a shoe box) is divided into five compartments of increasing size (with a width of $1,2,5,8$ and $14 \mathrm{~cm}$, respectively). 


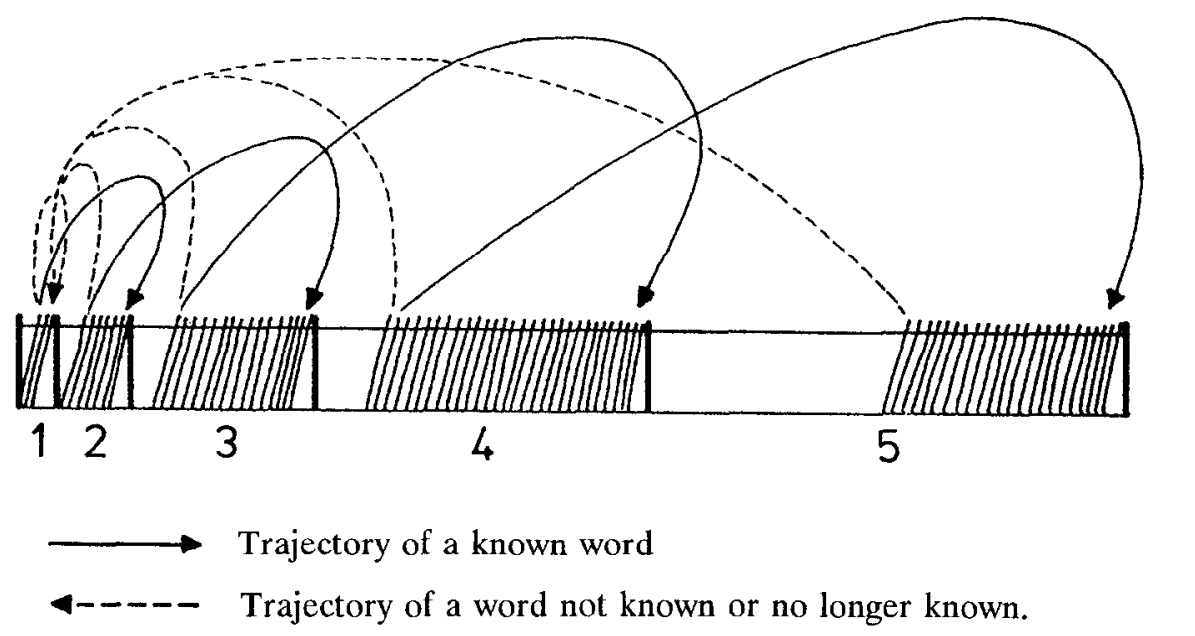

Fig. 3. Leitner's hand compuler (1972).

The procedure in using the hand computer is as follows (see Fig. 3). Every word to be learned is put on a card ${ }^{11}$ : the foreign-language word on one side, the translation on the other (preferably in a different colour so that it is immediately clear which is the front and which is the back). The cards are placed in compartment 1 (30-40 cards at the most), after which they are gone through. What the learner knows is moved on to compartment 2, what (s)he does not know is put in the back of compartment 1 again. When there are only three words left in compartment 1 , the compartment is replenished with $30-40$ new words, and words can be learned and moved on again. After this has been repeated a few times, compartment 2 becomes filled up, and the time is ripe to repeat the words in compartment 2: what the learner still knows goes into compartment 3; what (s)he does not immediately recall goes back into the back of compartment 1. In this way about the breadth of a finger is cleared out of compartment 2 . This is also the principle of the hand computer in a nutshell: whatever is "known" goes into the next compartment; anything "not known/no longer known" should go back into compartment 1.

After some time compartments 3 and 4 will become filled up. In that case the same procedure is adopted as in compartment 2 . When eventually compartment 5 also becomes filled up and room is to be made there too, the learner may in principle throw the cards away if (s)he still knows them: for by then (s)he has seen them so often, and so much distributed in time at that, that we may speak of real knowledge. An alternative possibility, not mentioned by Leitner, is working with a compartment 5 that is so big that it need not be cleared out. In this case the cards may just be kept, while occasionally a sample of 10 cards is drawn from it in order to see if the words are still known. So in this way compartment 5 contains the learner's complete word knowledge.

On comparing Leitner's hand computer with Landauer and Bjork's expanding rehearsal strategy, we note the same principle at work, namely repetition through ever bigger intervals. 
However, there is a difference in emphasis: Landauer and Bjork begin with very small intervals, and continue for less time; Leitner begins with a bigger interval, but continues for longer. An advantage of the latter is that the learning effect is better ensured in the long run. A second advantage of Leitner's system over Landauer and Bjork's is the automatism with which repetition through ever bigger intervals takes shape: the increasing size of the compartments automatically entails ever bigger intervals. A less strong point of the hand computer is that in learning words of a high degree of difficulty the number of 30-40 words in compartment $\mathbf{l}$ is sometimes too great to get hold of the words, ${ }^{12}$ as a result of which it takes relatively long for a word to end up in compartment 2 . However, this problem is readily solved by reducing the set of words worked with in compartment 1 , say to 15-20 words. By way of a warm-up for the learning process it is even possible to apply the expanding rehearsal strategy within compartment 1 .

\section{ADVANTAGES OF WORD CARDS AND HAND COMPUTER}

Working with word cards and hand computer has a number of important learningpsychological advantages over learning of words with the help of lists, in whatever form. These have been partly discussed already, but it seems useful to completely list them below:

(a) While learning the learner concentrates on those words he does not know yet: the words(s) he does know, or has learned in the meantime because they were not difficult, (s)he can put aside or-with the hand computer-move to compartment 2 straight away. In this way each word gets from each learner precisely the amount of attention it needs. In this way the available time is used cfficiently [cf. Atkinson (1972)].

(b) The order of a series of words to be learned is flexible. Consequently the position of a word to be learned in a series no longer wrongly offers any help. While working with word cards the order can be changed by shuffling the cards; while working with the hand computer the order automatically changes for "known" words constantly disappear from compartment 1 , new ones are added to it, some old ones return, etc.

(c) With the hand computer the knowledge of all words learned is checked at various moments (distributed practice) by means of ever bigger intervals (expanding rehearsal). In this way the words are repeated. Because of the long period that it takes for a card to be processed through the hand computer-the hand computer described can contain over 1000 cardslong-term knowledge is much better ensured. As the necessary repetition checks for known words remain limited, sufficient time is left for the learning of new words, as well as for forgotten words, which again receive full attention.

Besides these advantages that meet the objections pointed out in Section 3 against the learning of words with the help of lists, some other learning-psychological advantages may be mentioned:

(d) By writing the cards the learner pays more attention to the word form of the foreignlanguage word than is usually the case. ${ }^{13}$ Research has shown that this writing down of the foreign language word has a positive effect on the productive retention (Thomas and Dieter, 1987: p. 250).

(e) During learning (receptively or productively) the learner does not at once see the translation of the word to be learned. This stimulates him/her to first think before checking whether ( $\mathrm{s}$ )he knows the word (retrieval practice). In this way the mental activity during learning corresponds with that during later testing. 
(f) As learning is supported by motor, manual activity - the learner is constantly handling the cards-(s)he is better concentrated on the task, something which appears to work especially in learners who are by nature easily distracted.

To these learning-psychological advantages some motivational advantages may be added, especially for weak learners:

(g) Learners have a strong affective bond with the material for they have made the cards themselves. The deck of cards is something truly theirs.

(h) Learners see the results of their learning (experiencing of success): an ever growing pile of cards with words they already know.

(i) Learning words is no longer a dull cognitive activity, but a real activity with playful elements.

Finally, it may be said in favour of the hand computer that learners are taught a good vocabulary-learning strategy which is also usable for other languages as well as for other subjects.

\section{APPLICATIONS}

Working with word cards and/or a hand computer is suitable for all types of learners, for all levels, and even for all kinds of subjects [e.g. history (dates), biology (terms), chemistry (formulas)]. Depending on the situation, everybody can choose his/her own form. The various applications of word cards and hand computer are shown in Table 2.

Table 2. Applications of word cards and hand computer
(1) System:
* Only word cards (without repetition system)
(2) Design:
* Hand computer (i.e. word cards with repetition system)
* (Shoe) box with five compartments
* A series of five audio cassette boxes
(3) Learner:
* CALL-program
(4) Organization:
(5) Subject mater:
(6) Source:
(7) Option: $\quad$ * All unknown words
Strong [cf. Stevick (1989)]
* Beginner
* Advanced
* In class (i.e. all learners)
* Individually (e.g. only weak students)
* Isolated words
* Words in sentences
* Collocations (frequently occurring word-combinations)
* Lexical phrases ${ }^{14}$
* Idioms (meaning cannot be derived from constitutent parts)
* Language functions
* Scntences
* Lexicalized grammar
* Pronunciation
* Coursebook
* Vocabulary book
* Independent reading
(8) Desired level of knowledge: * Receptive
* Productive 
There are various types of concrete examples of applications of word cards and hand computer. A number of these will be briefly discussed below, according as they are systems with or without repetition system:

Word cards (without repetition system):

- In the secondary school where the second author is employed weak learners learn their words from a French vocabulary book with the help of word cards (all words or just the problematic ones).

- Westphal (1977) reports an informal learning experiment in which some high school classes worked with (French) word cards for 1 year.

- Successful language learners also work with word cards [cf. Stevick (1989: pp. 30-32, $111-113)]$.

- Commercial card systems, with which the most important words of various foreign languages can be learned, are being marketed by various publishers in various countries. The size of these systems varies from some hundreds of items to sometimes 6000 items, i.e. words, sentences, or parts of sentences.

\section{Hand computer (word cards with repetition system):}

- In various secondary schools in the Netherlands positive results have been obtained with the hand computer in (shoe) box model for the learning of the words of the course (in French, German), e.g. dealt with in class in the first form of secondary school [cf. Mondria and Mondria-de Vries (1991)l, and by weaker learners in the higher forms.

- The first author of this article has been using for some years as a hand computer a series of audio-cassette boxes ${ }^{15}$ filled with cards in order to raise his academic English to a higher level. The advantage of this shape is that the material can easily be carried, and can be gone through at any spare moment.

- There are also commercial organisations with repetition systems: the German publishers Klett and Langenscheidt, for example, have been marketing systems for French and English with a size of 600-2000 items. These commercial card systems, however, are not suitable for the English-speaking market because they depart from German as a mother tongue. From the fact that these card systems have been available everywhere in Germany for many years, it may be inferred that it has been a success as a learning aid. The materials, which are not course-bound, are probably mostly used at home.

- CALL-programs which are based on the hand computer are also available now, e.g. in The Netherlands Mulder (1992), Van der Linden (1993a, b) and Mondria et al. (1994). With the exception of the first, the programs are parts of coursebooks, whereby each student has his/her own disc, so that (s)he will be able to learn both at home and at school.

The advantages of the computerized version over the manual one are that: (a) the timeconsuming business of writing cards is over, and (b) the computer has a motivational impact on many students. The disadvantages are: (a) the dependence on equipment (one can no longer learn words at any time and in any place); (b) a display is less stable and because of this more tiring than paper; (c) smaller files are chiefly worked with within a relatively short time, as a result of which the long-term repetition effect (larger files, longer periods) shows up less positively. 


\section{CONCI.USION}

The hand computer is a very efficient system for the intentional learning of words because of: (1) the use of cards in order to memorize words, and (2) the sophisticated repetition system to remember the words learned in the long run as well. By means of this set-up the memorizing of words with the hand computer is clearly superior to the memorizing of words by means of inflexible lists, in whatever form. Apart from that, the system is very flexible as regards contents (words, idioms, language functions, pronunciation, etc.) and as regards the learner (weak/strong, beginners/advanced, in class/individually, etc.).

However, even without a repetition system working with word cards has great advantages, but, when the learner does have the disposal of the cards, the deck of cards can easily be transformed into a hand computer which considerably increases the cost-effectiveness of learning with the help of cards.

\section{NOTES}

The definition of the notion of semanticizing is based on the first definition of this term given by Palmer [1968 (1917): p. 230].

2 An exception should be made for the (private) vocabulary notebook.

: For a survey of the inadequate repetition of vocabulary in coursebooks, see Nation (1990: p. 44).

${ }^{4}$ Figure adapted from Pimsleur (1967: p. 75).

5 Example taken from Baddeley (1990: p. 157).

"Also called "spacing effect" [cf. Anderson (1990: pp. 206-209)].

"Called "test-type practice" by Landauer and Bjork (1978).

\& The analysis is largely based on Baddeley (1990: pp. 156-157).

"Possible explanations for this are that remembering an item: (a) requires a greater mental effort [cf. the levels of processing theory by Craik and Lockhart (1972)], and (b) shows a closer resemblance with the performance required at eventual recall (Landauer and Bjork, 1978: p. 631).

10) A similar system is described in Kast et al. (1990), but no reference is made to Leitner (1972).

"Solid paper, format (using a shoe box) 10 by $15 \mathrm{~cm}$.

${ }_{12}$ For the relationship between degree of difficulty of words and length of list cf. Crothers and Suppes (1967).

${ }_{13}$ While working with children at a low level, the risk of spelling mistakes is largely overcome by making students check each other's cards.

${ }^{14}$ Collocations that have been assigned pragmatic functions (Nattinger and DeCarrico, 1992: p. 36).

15 This idea hats been derived fron Karl (1991).

\section{REFERENCES}

ANDERSON, J. R. (1990) Cognitive Psychology and its Implications (3rd edition). New York: Freeman.

ATKINSON, R. C. (1972) Optimizing the learning of a second-language vocabulary. Journal of Experimental Psychology 96, 124-129.

RADDFI FY, A. D. (1983) Your Memory: a U/ser's Guide. Harmondsworth: Penguin.

BADDELEY, A. D. (1990) Human Memory: Theory and Practice. Hove: Erlbaum.

BJORK, R. A. (1988) Retrieval practice and the maintenance of knowledge. In Gruneberg, M. M., Morris, P. E., and Sykes, R. N. (eds), Practical Aspects of Memory: Current Research and Issues, Vol. 1: Memory in Everyday Life, pp. 396-401. Chichester: John Wiley.

CRAIK, F. I. H. and LOCKHART, R.S. (1972) Levels of processing: a framework for memory research. Journal of Verbal Learning and Verbal Behavior 11, 671-684. 
CROTHERS, E. and SUPPES, P. (1967) Experiments in Second-language Learning. New York: Academic Press. EBBINGHAUS, H. (1885) Über das Gedächtnis. Leipzig: Von Duncker and Humblot.

HIGA, M. (1985) The psycholinguistic concept of 'difficulty' and the teaching of foreign language vocabulary. Language Learning 15 (3/4), 167179.

KARL, W. (1991) Lernen mit Karteien im fortgeschrittenen Englischunterricht. Fremdsprachliche Unterricht 2 , $14-20$.

KAST, B., SIXT, D. and WARGER, F. (1990) Die Lernmaschine. Fremdsprache Deutsch 3, 54-55.

LADO, R. (1964) Language Teaching: a Scientific Approach. New York: McGraw-Hill.

LANDAUER, T. K. and BJORK, R. A. (1978) Optimum rehearsal patterns and name learning. In Gruneberg, M. M. Morris, P. E. and Sykes, R. N. (eds), Practical Aspects of Memory, pp. 625-632. London: Academic Press.

LEITNER, S. (1972) So lernt man lernen. Freiburg: Herder (16th impression 1991).

MONDRIA, J. A. and MONDRIA-DE VRIES, S. (1991) Woorden leren met de 'handcomputer': Praktijkverslag van een leerexperiment met een bijzonder woordkaarjes-systeem. Levende Talen 465, 458-461.

MONDRIA, J. A.. MONDRIA-DE VRIES, S. and RABBAH, M. (1994). Vocabulaire-leerprogramma bij 'A toi maintenant!'. Zutphen: Thieme.

MULDER, R. (1992) Leren in Etappes. Lopik: Visiria.

NATION, I. S. P. (1990) Teaching and Learning Vocabulary. New York: Newbury Ilouse.

NATTINGER, J. R. and DECARRICO, J. S. (1992) Lexical Phrases and Language Teaching. Oxford: Oxford University Press.

OXFORD: R. L. (1990) Language Learning Strategies: What Every Teacher Should Know. New York: Newbury House.

PALMER, H. E. [1968 (1917)] The Scientific Study and Teaching of Languages (new edition by D. Harper). London: Oxford University Press.

PIMSLEUR, P. (1967) A memory schedule. Modern Language Journal 51 (2), 73-75.

REA, C. P. and MODIGLIANI, V. (1988) Educational implications of the spacing effect. In Gruneberg, M. M., Morris, P. E. and Sykes, R. N. (eds), Practical Aspects of Memory: Current Research and Issues, Vol. I: Memory in Everyday Life, pp. 402-406. Chichester: John Wiley.

RODGERS, T. S. (1969) On measuring vocabulary difficulty: an analysis of item variables in learning RussianEnglish vocabulary pairs. IRAL 7 (4), 327-343.

SARAGI, T., NATION, I. S. P. and MEISTER, G. F. (1978) Vocabulary learning and reading. System 6, 72-78.

SIEGEL, M. A. and MISSELT, A. L. (1984) Adaptive feedback and review paradigm for computer-based drills. Journal of Educational Psychology 76, 310-317.

STEVICK, E. W. (1989) Success with Foreign Languages: Seven who Achieved It and What Worked for Them. New York: Prentice Hall.

THOMAS, M. H. and DIETER, J. N. (1987) The positive effects of writing practice on integration of foreign words in memory. Joumal of Educational Psychology 79, 249-253.

VAN BERKEL, A. (1990) Orthodidactische gids voor het vreemde-talenonderwijs. Muiderberg: Coutinho.

VAN DER LINDEN, C. (1993a) Overhoorprogramma bij 'Grandes Lignes'. Groningen: Wolters-Noordhoff.

VAN DER LINDEN, C. (1993b) Overhoorprogramma bij 'Neue Welle'. Groningen: Wolters-Noordhoff.

VAN PARREREN, C. and SCHOUTEN-VAN PARREREN, C. (1978) Erwerb eines fremdsprachlichen Worschatzes. In Detering, K. and Högel, R. (eds) Englisch auf der Sekundarstufe 1, pp. 22-36. Hannover: Schroedel.

WEBER, H. and DENNINGHAUS, F. (1960) Vokabelheft oder Vokabelkartei. Praxis des neusprachlichen Unterrichts 7(4), 141-144.

WESTPHAL, P. B. (1977) In search of a systematic way with words. French Review 51(1), 59-64. 